\title{
OC34 - Paediatric rehabilitation: humanizing nursing care to children and their families
}

\author{
Ana Paula Marques França (Portugal)룰 Alda Rosa Barbosa \\ Mendes (Portugal) ${ }^{1}$; Mariana Inês Fernandes Barrias (Portugal) ${ }^{2}$ \\ ${ }^{1}$ Escola Superior de Enfermagem do Porto - Nursing School of Porto; ${ }^{2}$ Centro de \\ Reabilitação do Norte
}

Theme: Ethical issues - dignity and humanity.

Keywords: Ethics, humanization, nursing care, paediatric rehabilitation, paediatric nursing.

Introduction: The child with special health care needs in a rehabilitation center for their vulnerable condition requires a clinical practice centered on ethics and humanization.

Objectives: To know the parents' and nurses opinions on humanized care in a paediatric rehabilitation unit and to identify needs and strategies that promote the humanization of care in a paediatric rehabilitation unit.

Methods: Qualitative, descriptive, exploratory study, using interviews with nurses and questionnaires to parents of hospitalized children.

\begin{abstract}
Results: This study enhances the importance that nurses should have in human relationships, with special attention to each child and their parents, but also to the structural and functioning conditions of the unit.
\end{abstract}

Discussion: The results are in agreement with the literature, highlighting the particular aspects of children with special needs and their parents.

Conclusion: The results contribute to more humanized care and could be a basis for a Charter of Humanization.

\section{OC35 - Child Friendly Healthcare Initiative, implementation project in a paediatric department in Greece}

Barbara Boutopoulou (Greece) ${ }^{1}$; Andrew Clarke (United

Kingdom) ${ }^{2}$; Ioanna Christothanopoulou (Greece)';

Konstantinos Douros (Greece) ${ }^{1}$; Maria Tsirouda (Greece) ${ }^{1}$;

Vasiliki Papaevangelou (Greece) ${ }^{3}$

${ }^{1}$ 3rd Dept of Paediatrics, 'Attikon' Hospital; ${ }^{2}$ Public Health Development Lead (Children \& Families) - Lancashire Care NHS Trust; ${ }^{3} 3 r d$ Dpt of Paediatrics, National and Kapodistrian University of Athens School of Medicine, 'Attikon' Hospital 